IZA DP No. 7400

Seek and Ye Shall Find: How Search Requirements Affect Job Finding Rates of Older Workers

Patrick Hullegie

Jan C. van Ours

May 2013 


\title{
Seek and Ye Shall Find: How Search Requirements Affect Job Finding Rates of Older Workers
}

\author{
Patrick Hullegie \\ VU University Amsterdam, \\ Tinbergen Institute and Netspar \\ Jan C. van Ours \\ CentER, Tilburg University, \\ University of Melbourne, CESifo, CEPR and IZA
}
Discussion Paper No. 7400
May 2013

IZA
P.O. Box 7240
53072 Bonn
Germany

\author{
Phone: +49-228-3894-0 \\ Fax: +49-228-3894-180 \\ E-mail: iza@iza.org
}

\begin{abstract}
Any opinions expressed here are those of the author(s) and not those of IZA. Research published in this series may include views on policy, but the institute itself takes no institutional policy positions. The IZA research network is committed to the IZA Guiding Principles of Research Integrity.

The Institute for the Study of Labor (IZA) in Bonn is a local and virtual international research center and a place of communication between science, politics and business. IZA is an independent nonprofit organization supported by Deutsche Post Foundation. The center is associated with the University of Bonn and offers a stimulating research environment through its international network, workshops and conferences, data service, project support, research visits and doctoral program. IZA engages in (i) original and internationally competitive research in all fields of labor economics, (ii) development of policy concepts, and (iii) dissemination of research results and concepts to the interested public.
\end{abstract}

IZA Discussion Papers often represent preliminary work and are circulated to encourage discussion. Citation of such a paper should account for its provisional character. A revised version may be available directly from the author. 


\section{ABSTRACT}

\section{Seek and Ye Shall Find: How Search Requirements Affect Job Finding Rates of Older Workers}

Unemployment insurance recipients in the Netherlands were for a long time exempted from the requirement to actively search for a job when they reached the age of 57.5. We study how this exemption affected the job finding rates of the recipients involved. We find evidence that the job finding rate of unemployed workers who were getting close to the age of 57.5 is reduced in anticipation of the removal of the search requirement. In addition we find a large negative effect on job finding rates of the actual removal of the search requirement. Apparently, even for persons with seemingly poor job prospects search requirements have a positive effect on finding rates.

JEL Classification: C41, H55, J64, J65

Keywords: eligibility criteria, unemployment benefits, job finding, older workers

Corresponding author:

Jan C. van Ours

Tilburg University

P.O. Box 90153

5000 LE Tilburg

The Netherlands

E-mail: vanours@uvt.nl

\footnotetext{
* We thank Jaap Abbring, Jonneke Bolhaar, Adriaan Kalwij, Peter Kooreman, Tobias Klein, Maarten Lindeboom, Bas van der Klaauw, and seminar participants at Tilburg University and VU University Amsterdam for helpful comments. The estimates in this paper are based on own calculations using various micro datasets made available through a remote access facility by Statistics Netherlands. We thank Sander Tuit for constructing the dataset we use in our analysis.
} 


\section{Introduction}

The labor market position of older workers is usually solid when they are employed, as it is unlikely that they are laid off. When they lose their job however, getting back to work it is much harder for them than for prime age workers. This is observed in almost all OECD countries, although there exists considerable variation among the member countries (OECD, 2006).

The poor employment prospects of older unemployed workers are due to a combination of demand and supply side factors. As for the demand side, employers may believe that the wage of older workers is higher than their productivity or they may think that the skills of older workers are outdated and not worthwhile to invest in. Hence, employers prefer to hire prime age workers rather than older workers. As for the supply side, the low percentage of older workers returning back to work may be due to the generosity of the unemployment system. In a relatively generous unemployment system, older workers may consider unemployment as a pathway into (early) retirement (Heyma, 2001; Gruber \& Wise, 1998).

In order to offset the disincentive effects of unemployment insurance (UI) programs on job search behavior, receiving UI benefits is often conditional upon being available for work and actively searching for a job (Grubb, 2001). However, in many European countries the poor labor market prospects of older workers are taken into account and UI eligibility criteria are less strict for them (OECD, 2006). They, for example, do not have to meet the requirement to actively search for a job. If indeed the labor market position of older workers is weak, imposing a search requirement is not useful. Nevertheless, it may also be the case that older workers can influence their job finding. Then abolishing a search requirement may be counterproductive and reinforce their weak labor market position.

We examine how job search requirements for older workers in the Netherlands affected their job finding rates. In our analysis we exploit the following policy. Prior to January 1, 2004, UI recipients had to actively search for a job up until age 57.5. After age 57.5, UI recipients were exempted from the search requirement. We find that the removal of the search requirement at age 57.5 had a large negative effect on the job finding rate. In fact, already some time before the search requirement was removed the job finding rate was reduced. Apparently, unemployed workers who are getting close to the age of 57.5 reduced their search intensity in anticipation of the removal of the search requirement. From this we conclude that even workers with a weak labor market position are able to react to the requirement that they should actively search for a job. Older workers seem to have at least some influence over their labor market position.

Our paper is related to Heyma and Van Ours (2006) who present an early and unfinished 
analysis of the effect of the search requirement on the job finding rate. Our paper is also related Lammers, Bloemen, and Hochguertel (2013), who utilize the same variation in UI eligibility criteria as we do. They study how changes in search requirements for older UI recipients affect the transition rates to employment, early retirement and disability insurance. They find that stricter search requirements significantly increase the outflow to work, as well as outflow to disability insurance. Our paper differs from Lammers et al. (2013) as we not only examine the effect of the removal of the search requirement, but also study search behavior in the period just prior to the removal of the search requirement. Furthermore, we follow a different identification strategy for reasons to be discussed in more detail in Section 4.

The contribution of our paper to the literature is twofold. First, our findings are relevant for public policy in the context of an aging society. To alleviate the burden of population aging on government budgets, many OECD countries have implemented various reforms that encourage prolonged working lives. An important aspect of these reforms is to get older unemployed workers back to work, and as a consequence, UI eligibility criteria are often no longer less stringent for older workers.

Second, we contribute to the literature that links search requirements to job finding rates. Often it was not possible to establish the separate contribution of search requirements to job finding rates as search requirements are often combined with job finding services (see Meyer (1995) for an overview). The Washington Alternative Work-Search Experiment and the Maryland UI Work Search Experiment were designed to study the impact of different work-search policies for UI recipients. Johnson and Klepinger (1994) report findings from the former experiment. They conclude that no alternative experimental policy (no search requirements, individual tailored requirements, job finding services) significantly increases the length of the unemployment spell relative to the status-quo search requirements, which involved three job applications per week. Klepinger, Johnson, and Joesch (2002) report findings from the Maryland experiment and conclude that stricter search requirements or employer contact verification reduce the length of the unemployment spell. Furthermore, they find no evidence that wages, earnings, and total income are affected. This suggests that higher nonmonetary costs of continued benefit receipt are compensated by more intensive job search rather than by a reduction of the reservation wage. Ashenfelter, Ashmore, and Deschênes (2005) report findings from yet another field experiment that was designed to measure whether stricter enforcement and verification of work search behavior alone decreases unemployment claims and benefits paid. In contrast to the results of Johnson and Klepinger (1994) and Klepinger et al. (2002), their results do not indicate that verification of search behavior caused shorter unemployment spells 
or lower total UI benefit payments.

The remainder of this paper is organized as follows. Section 2 discusses the relationship between search requirements and job search from a theoretical viewpoint. Section 3 provides details on the Dutch UI system. Section 4 describes the data and presents an exploratory analysis. Section 5 discusses our econometric approach. Empirical results and various sensitivity analyses are presented in section 6 . Finally, section 7 concludes.

\section{Search requirements and job search}

Exempting unemployed workers older than a certain age from a search requirement introduces non-stationarity in a job search model. Since UI recipients who do not comply with rules will receive a benefit sanction, a job search model describing the particular feature of the Dutch UI system that we study has to combine elements of a non-stationary search model, like Mortensen (1977) or Van den Berg (1990), with that of job search model with sanctions, like Abbring, Van den Berg, and Van Ours (2005).

Imposing a job search requirement may stimulate UI recipients who do not like to work, or those who do not like to search for a job. To be more precise, we can consider the following three groups of UI recipients. For the first group the optimal search effort in the absence of sanctions is higher than the required minimum number of contacts. They will exert the same effort regardless of whether or not search requirements exists. For the second group the optimal search effort in the absence of sanctions is lower than the required minimum number of contacts. They will exert as much effort as required for as long as necessary. For the third group the optimal search effort in the absence of sanctions is also lower than the required minimum number of contacts but they are willing to take the risk that a sanction is imposed. The search effort of UI recipients belonging to group 2 will show a discontinuity at the moment the search requirement is abolished. By contrast, the search effort of UI recipients from groups 1 and 3 will not show such a discontinuity. Specifically, for members of groups 3 search effort continuously decreases either because of the belief that the probability of a sanction decreases as they get closer to the moment of abolishment and/or because of the anticipated increase in the value of unemployment.

If additionally the reservation wage increases in anticipation of the higher value of unemployment, then, in the absence of duration dependence effects, the job finding rate will continuously fall up to the moment of abolishment for all three groups, and be constant afterwards. Moreover, for members of group 2, the job finding rate has a discontinuity at the moment of 
abolishment because of the discontinuity in search effort.

The population of UI recipients will be a mixture of the three groups described above. Theoretical considerations suggest, unambiguously, that empirically we should find anticipation effects. Whether or not we find a discontinuity at the moment of abolishment depends on the relative size of group 2 .

\section{The Dutch Unemployment Insurance System}

In the Netherlands unemployed workers are entitled to unemployment benefits if they (1) are involuntarily and not culpably unemployed, i.e. they did not resign or were not fired for pressing reasons; (2) lose earnings for at least five working hours per week, or earnings for half of their working hours if employed for less than ten hours per week; (3) have been employed for at least 26 consecutive weeks out of the 39 weeks prior to unemployment; and (4) who are available for work.

If an unemployed worker meets the conditions mentioned above he or she is eligible for short-term benefits, which can be received for six months and which amount to 70 percent of the minimum wage. If in addition to the "26-out-of-39- weeks condition" he also received wages for at least 52 days in the four calendar years during the five years prior to unemployment, he qualifies for wage-related benefits. Depending on labor experience these benefits last for at least six months up to a maximum of five years. ${ }^{1}$

Labor experience is calculated as the number of years in the 5 calendar years prior to unemployment in which the person received wages for at least 52 days, plus the number of calendar years between the year that the person turned 18 and the 5 years prior to unemployment. As a result of the "4-out-of-5-years condition," the potential duration for wage-related benefits depends almost completely on the age at which the person becomes unemployed. A UI recipient with wage-related benefits receives 70 percent of the average wage received in the job from which he became unemployed in the 26 weeks prior to unemployment. The level is regularly adjusted to a general index of wages and limited to a maximum, which amounted to 152.62 Euro per day in 2001.

In 2001 the duration of extended benefits only depended on age. Persons who became unemployed before the age of 57.5, were entitled to two years of extended benefits, whereas older persons were entitled to 3.5 years. Thus, a person who became unemployed after the age

\footnotetext{
${ }^{1}$ With a labor market experience of 30-35 years the potential duration of the wage-dependent benefits is 3 years, with 35-40 years of experience it is 4 years, and with more than 40 years of experience it is 5 years.
} 
of 57.5 and who met the conditions for wage-related benefits, had a potential benefit duration of at least four years, but it may have been as long as 7.5 years. He would therefore receive UI benefits until the mandatory retirement age of $65 .^{2}$ As of 11 August 2003, extended benefits are abolished, except for persons 50 years and older. For them extended benefits are means-tested such that those with a household income of 70 percent of the minimum wage or more do not receive extended benefits.

In most countries administrators of unemployment insurance typically impose job search requirements on the recipients to partially offset the negative impact unemployment benefits have on job search. In the Netherlands, up to January 1, 2004, UI recipients had to actively search for a job until the age of 57.5. Beyond that age they would still be obliged to accept job offers but a job search requirement was obsolete. From January 1, 2004, onwards, all new recipients were required to actively search for a job. Regulations specified that a person needed to apply to at least four jobs in four weeks while these activities had to be reported at regular time-intervals to the employment office. ${ }^{3}$

In practice the number of job applications a recipient needed to make were tailored to: (1) the conditions of the regional labor market; (2) the number of "suitable" job opportunities; and (3) the medical situation and age of the person. Whether or not a recipient fulfilled the search requirement was decided upon by the case worker of the employment office. This worker also decides what is considered to be a "suitable" job, taking into account a person's previous job, his education, and earnings. Generally, the longer the unemployment duration lasts the broader the definition of "suitable" work becomes.

If a recipient does not comply with the rules, a benefit sanction may be applied. The noncomplying person can get a temporary or a permanent reduction in benefits (full or partial). Concerning the severity of the sanction Abbring et al. (2005) write: "In practice, the temporary partial reduction of the benefits ranges from 5 percent during 4 weeks to 25 or 30 percent during 13 weeks." These numbers are percentages of the previous wage or replacement-ratio percentage points. For example, a sanction of 20 percent on a worker with UI benefits equal to 70 percent of his previous wage is left with UI benefits equal to 50 percent of his previous wage. $^{4}$

\footnotetext{
${ }^{2}$ It is known that in the past collecting UI benefits has been used as a retirement pathway (Heyma, 2001; Gruber \& Wise, 1998).

${ }^{3}$ The stated employer contacts may have been verified by the employment office but this did not occur across the board.

${ }^{4}$ See Abbring et al. (2005) for further details.
} 


\section{Data and exploratory analysis}

\subsection{Data and sample selection}

We use administrative data from Statistics Netherlands which are informative about unemployed persons who collect UI benefits. We use data on the inflow into unemployment in 2001 and 2004. The data contain the start and end date of UI-benefit spells (with censoring at 31 December 2005); the reason for termination of UI-benefits; the type of benefits; the number of hours for which UI-benefits are collected; and whether unemployment is entered from employment or otherwise, like a period of sickness. Personal characteristics in the data include gender, age, marital status, educational levels, nationality, and a profiling indicator consisting of four levels of increasing "distance to the labor market." Based on the reported educational level, persons are stratified into three different classes: primary, secondary and tertiary education. The indicator for marital status treats cohabitation as married. "Distance to the labor market" is included by a dummy variable (phase 1) that equals one if the person has a "strong" labor market position according to the classification of the employment office.

To study the effect of the removal of the search requirement we select workers who became unemployed in 2001 at an age between 55.5 and 57.5 for our main analysis. These persons are required to search for work as of the moment they become unemployed and are exempted from it as soon as they reach the age of 57.5. ${ }^{5}$

In contrast to Lammers et al. (2013) we do not include workers older than 57.5 years at inflow into our sample, and conduct a regression discontinuity type of analysis, because of the following concern. In 2001 the unemployment system contained strong incentives for workers to become unemployed after age 57.5, as then UI benefits could be received until the mandatory retirement age (65 at that time). Thus, firms and workers could try to manipulate the age at entry into unemployment. For example, firms might be willing to offer their employees not to lay them off until they are just older than 57.5. ${ }^{6}$ Tuit and Van Ours (2010) provide some support for this argument by showing that the inflow into the unemployment system shows a spike just after age 57.5 in 2001 but not in 2004 (see also figure 1). Furthermore, the share of UI recipients

\footnotetext{
${ }^{5}$ Workers who became unemployed in 2001 at an age younger than 55.5 faced different rules than those older than 55.5 when they were still unemployed at January 1, 2004. This is due to the rules governing the transition to the new policy. Therefore, we select workers older than 55.5. Since we do not have data on UI records prior to 2001 we cannot use them in our analysis. UI recipients who became unemployed in 2002 and who were older than 56.5 and younger than $\mathbf{5 7 . 5}$ faced the same rules as the UI recipients in our sample.

${ }^{6}$ Such a response would invalidate the regression discontinuity assumption that the unemployment duration for workers just passing the age threshold is informative about the counterfactual duration for workers who became unemployed just before the age threshold. See also McCrary (2007).
} 
with a strong labor market position is much higher in the age group 55.5-57.5 (about 85\%, see Table 1) than in the age group 57.5-59.5 (about 75\%).

In our analyses, we further focus on persons with a Dutch nationality, thus abstaining from issues on the labor market position of immigrants. Finally, we select unemployed workers who are non-seasonally full-time unemployed. Table 1 contains descriptive statistics for both 2001 and 2004 on the covariates we use in the analysis. Perhaps most interesting is the high percentage of the UI recipients in our sample who have a "strong" connection to the labor market according to the employment office.

\subsection{Exploratory graphs}

Figure 2 shows the relationship between the job finding rate and the duration of unemployment for workers who entered the UI system before age 57.5. Clearly, in 2004 the job finding rates are lower than in 2001. After about 6 months the job finding rates are very small.

To provide graphical evidence on how the abolition of the search requirement at age 57.5 affected the job finding rates, figure 3 shows the relationship between the relative monthly job finding rate and the months in relation to age 57.5. The top graph is based on workers entering unemployment before age 57.5, whereas the bottom graph is also based on workers entering after age 57.5. The job finding rate is computed for groups of workers according to their age of inflow and duration of unemployment (in months). The relative monthly job finding rate equals the average of the job finding rate of the (age at inflow, duration) combinations that equal a given month in relation to age 57.5 divided by the a average job finding rate over the window shown in the graph (i.e. twelve months prior to 57.5 until 12 months afterwards). ${ }^{7}$ In the absence of duration dependence, a value of 1.5 represents a 50 percent increase in the monthly job finding rate. However, it is unlikely that there is no duration dependence effect. Hence, the interpretation of the level of the relative job finding rates is not straightforward. The graphs are still informative, however, about a possible discontinuity in the job finding rate at age 57.5, because there is no reason to think that duration dependence is discontinuous at that age. In figure 3 both graphs show a drop to a lower job finding rate after age 57.5 in 2001 . However, this drop does not occur exactly at age 57.5 but a few months later. For 2004 such a drop does not seem to occur. By contrast to the bottom graph, the relative job finding rates in the top graph tend to zero after age 57.5. This is explained by the fact that in the top graph only

\footnotetext{
${ }^{7}$ For example, the job finding rate at month -1 (i.e. age $57 \frac{5}{12}$ ) is the average of (i) the job finding rate for workers getting unemployed at age $57 \frac{4}{12}$ and finding a job within one month, (ii) the job finding rate for workers getting unemployed at age $57 \frac{3}{12}$ and finding a job in their second month of unemployment, and so forth.
} 
workers younger than 57.5 years at inflow are used and that the job finding rate is basically zero after 6 months (see figure 2)

A reason why the drop in 2001 does not occur at age 57.5 may be the fact that we do not have information on how the removal of the search requirement was precisely operationalized. Thus we do not know whether, for example, the UI recipient was relieved from the obligation to search as of the first day of the month in which he turned 57.5, or whether this was from the first day of the next month. Furthermore, the age of the UI recipients is only recorded in months. Thus, even if we would now exactly when UI recipients were relieved from the search requirement, the incomplete measurement of age would still prevent us from knowing as when the UI recipients are relieved from it in practice. In the duration model to be discussed in the next section we assume different moments at which the search requirement is abolished and find that our conclusions are not sensitive to these different assumptions. Furthermore, we formally model the imprecise measurement of age.

\subsection{Exploratory analysis}

To further explore whether incentive effects are present we group the observations in the first 12 unemployment duration months and 24 age of inflow months (age 55.5 to 57.5) from the inflow in the two calendar years 2001 and 2004 into 576 "cells". For each of these "cells" we calculate the job finding probability. Then, we estimate a linear probability model in which the average job finding probability in month of duration $t$ conditional on age at inflow $\alpha_{j}(\mathrm{j}=1, . ., 24)$ and current age $a$ is specified as follows:

$$
\begin{gathered}
\theta\left(t \mid \alpha_{j}, a, d_{2004}\right)=\alpha_{j}+\alpha_{t}+\delta_{1} 1(57.25 \leq a<57.5) d_{2001}+\delta_{2} 1(t \geq 57.5) d_{2001}+ \\
\delta_{3} 1(57.25 \leq a<57.5) d_{2004}+\delta_{4} 1(t \geq 57.5) d_{2004}+\beta d_{2004}+\varepsilon
\end{gathered}
$$

The $\alpha_{t}$ represent 11 duration fixed effects, $\delta_{1}\left(\delta_{3}\right)$ measures the anticipation effect in 2001 (2004), and $\delta_{2}\left(\delta_{4}\right)$ is the treatment effect in 2001 (2004), i.e. the effect of the abolition of the search requirement. Finally, $\beta$ represents the effect of the year of inflow and $\varepsilon$ is an error term. If the search requirement has an effect on the job finding rates we expect $\delta_{1}$ and $\delta_{2}$ to be negative and significantly different from zero while $\delta_{3}$ and $\delta_{4}$ are expected to be insignificantly different from zero as in 2004 there was no change in search requirement at age 57.5.

The parameter estimates are presented in the first two columns of table 2 . The first column shows that indeed in 2001 both the anticipation effect and the treatment effect are negative, but the treatment effect is not significantly different from zero. In 2004 this is there is neither 
a significant anticipation nor treatment effect. Furthermore, the average job finding rates in 2004 are substantially lower than in 2001 . The second column shows that if we impose the anticipation effect and treatment effect to be zero in 2004, the anticipation effect and treatment effect in 2001 are negative and significantly different from zero. The third and fourth column show similar parameter estimates based on the first 6 months of outflow from unemployment. These parameter estimates tell the same story, although the anticipation effect in 2001 is now somewhat bigger and the treatment effect is no longer significantly different from zero.

\section{Statistical model}

We assume that differences in transition rates from unemployment to work can be characterized by observed time-varying covariates $(z(t))$, age at inflow $(\tau)$, other observed time-invariant covariates $(x)$, an unobserved random variable $(v)$, and the elapsed duration of unemployment itself $(t)$. The job finding rate at time $t$ conditional on $z(t), \tau, x$ and $v$, denoted by $\lambda(t \mid z(t), \tau, x, v)$, is assumed to have a mixed proportional hazard specification (see, e.g., Lancaster, 1990; Van den Berg, 2001)

$$
\lambda(t \mid z(t), \tau, x, v)=\lambda_{0}(t) \exp \left(\alpha^{\prime} z(t)+\beta \tau+\gamma^{\prime} x+v\right)
$$

where $\beta$ is a parameter and $\alpha^{\prime}$ and $\gamma^{\prime}$ are vectors of parameters. Furthermore, $\lambda_{0}(t)$ represents duration dependence - the baseline hazard - in the form of a flexible piecewise-constant function

$$
\lambda_{0}(t)=\exp \left(\sum_{j=1}^{J} \mu_{j} 1_{j}(t)\right),
$$

where $1_{j}(t)$ is the indicator function that equals 1 if $t$ is in the $j$-th interval and 0 otherwise, and where the $\mu$ 's are parameters to be estimated. We distinguish four time intervals: less than 3 months, 3-6 months, 6-12 months, and 12 and more months. Because we also estimate a constant term, we normalize the duration dependence parameter of the first interval to zero $\left(\mu_{1}=0\right)$.

Let $t^{a}$ be the time until a person starts to anticipate the abolishment of the search require- 
ment and let $t^{s}$ be the time until abolishment, then in our baseline specification we specify ${ }^{8}$

$$
\alpha^{\prime} z(t)=\alpha_{1} 1\left(t^{a} \leq t<t^{s}\right)+\alpha_{2} 1\left(t^{s} \leq t\right) .
$$

The effect of the anticipation of the abolishment of the search requirement is captured by $\alpha_{1}$ and the effect of the abolishment itself by $\alpha_{2}$. In our baseline specification we assume that $t^{a}=t^{s}-3$ months. Since there is (a priori) no reason why UI recipients start anticipating the removal 3 months in advance, we also consider specifications with different anticipation intervals as part of the sensitivity analyses.

All persons in our sample have a search requirement at the start of their unemployment spell, i.e., $t^{0}<t^{s}$, where $t^{0}$ is the moment at which a person becomes unemployed. Furthermore, when our sample members are unemployed long enough and reach the age of 57.5, the search requirement is removed. We do not require that a person is unemployed before the moment at which we conjecture he starts to anticipate the removal of the search requirement, thus it can be that $t^{a}<t^{0}$ for some persons in our sample. Let $t^{u}$ denote the completed duration of the unemployment spell (measured in days). Then, the following situations can occur within our sample:

1. $t^{0}<t^{a}<t^{s}<t^{u}$ : the worker enters unemployment before the start of the anticipation period and finds a job after age 57.5;

2. $t^{0}<t^{a}<t^{u}<t^{s}$ : the worker enters unemployment before the start of the anticipation period and finds a job before age 57.5;

3. $t^{0}<t^{u}<t^{a}<t^{s}$ : the worker enters and leaves unemployment before the start of the anticipation period;

4. $t^{a}<t^{0}<t^{s}<t^{u}$ : the worker enters unemployment during the anticipation period and finds a job after age 57.5;

5. $t^{a}<t^{0}<t^{u}<t^{s}$ : the worker enters unemployment during the anticipation period and finds a job before age 57.5;

The identification of the anticipation and the $57.5+$ (or treatment) effect is determined by which of the five above cases apply. The identification of the anticipation effect is through cases 1,2 , 4 and 5. For the identification of the 57.5+ effect cases 1 and 4 are important. In cases 4 and 5

\footnotetext{
${ }^{8}$ It is possible to allow the hazard rate to depend on time $(t)$, and the time until the removal of the search requirement $\left(t^{s}\right)$, because $t^{s}$ is a time-varying covariate that varies within the sample. This is analog to the reasoning in papers studying the impact of the potential benefit duration on the duration of unemployment; they can allow the hazard to depend on time and the time until exhaustion (see e.g. Katz \& Meyer, 1990; Meyer, 1990). Note that it is not possible to separately identify the anticipation effect and the age effect.
} 
there is a correlation between anticipation effect and the "age at inflow effect." Table 1 provides information about the relative size of each of these five groups, with $t^{a}=t^{s}-3$ months.

The unobserved heterogeneity component $v$ is assumed to follow a discrete distribution with two points of support, $\left(v_{1}, v_{2}\right)$, where $\operatorname{Pr}\left(v=v_{1}\right)=p, \operatorname{Pr}\left(v=v_{2}\right)=1-p$, and $p=\exp (\eta) /(1+\exp (\eta))$. We normalize $v_{1}$ to zero and estimate $v_{2}$.

A key variable in our analyses is age at inflow. If age at inflow would be precisely measured, the loglikelihood contribution of the $i$-th person would be

$$
L_{i}=d_{i} \log f\left(t_{i}^{u} \mid z_{i}(t), \tau_{i}, x_{i}, t_{i}^{a}, t_{i}^{s}\right)+\left(1-d_{i}\right) \log S\left(t_{i}^{u} \mid z_{i}(t), \tau_{i}, x_{i}, t_{i}^{a}, t_{i}^{s}\right)
$$

where $d_{i}=1$ if the $i$-th person's spell is uncensored and $d_{i}=0$ if censored, where $f(\cdot)$ denotes the probability density function and $S(\cdot)$ the survivor function, and where $t_{i}^{a}$ and $t_{i}^{s}$ depend on the age at inflow. In the data, however, age at inflow is reported in years and months only, and hence it is imprecisely measured. Thus, the observed age at inflow is lower than the actual age at inflow. How much it is lower depends on the month of birth, but unfortunately we do not have this information nor can it be inferred from the information we do have. Therefore, we proceed as follows: let $\tau$ denote the actual age at inflow, $\hat{\tau}$ the observed age at inflow and assume that $\tau=\hat{\tau}+\varepsilon$, where $\varepsilon$ follows a discrete uniform distribution with $\{0,1, \ldots, 30\}$ as possible outcomes, each with probability $1 / 31$. The loglikelihood contribution for person $i$ can then be written as

$$
L_{i}=\frac{1}{31} \sum_{k=0}^{30}\left[d_{i} \log f\left(t_{i}^{u} \mid z_{i}(t), \tau_{i}+k, x_{i}, t_{i}^{a}, t_{i}^{s}\right)+\left(1-d_{i}\right) \log S\left(t_{i}^{u} \mid z_{i}(t), \tau_{i}+k, x_{i}, t_{i}^{a}, t_{i}^{s}\right)\right] .
$$

\section{Parameter estimates}

In the absence of detailed information on how the removal of the search requirement was operationalized, we assume in our baseline specification that a person was exempted from it as of the first day of the month in which he turned 57.5. Furthermore, we assume that UI recipients start to anticipate the removal of the search requirement three months before it actually removed. The baseline parameter estimates based on the 2001 inflow sample are reported in the first two columns of Table 3. The estimates in panel $a$. indicate that, in anticipation of the removal of the search requirement, UI recipients significantly lower their search efforts. In the three months proceeding the removal, the job finding rate is 25 percent $(\approx 1-\exp (-0.30))$ lower than in the period before anticipation. When the search requirement is actually removed 
(the $57.5+$ effect) the job finding rate decreases by another 34 percentage points. This is a significant effect, showing that even for persons with a rather weak labor market position a job search requirement is an effective instrument in getting them back to work. Male workers have a higher job finding rate than otherwise equivalent female workers. Unemployed workers with secondary or tertiary education have a lower job finding rate. Also, the job finding rate for UI recipients with a relatively strong labor market position is more than twice as high as that of a recipient with a weaker labor market position.

In our baseline specification age at inflow is not included as one of the covariates. This seems reasonable since the range of age at inflow is rather narrow. However, to investigate whether this was the right choice, we also estimated a model including age at inflow as one of the covariates. The relevant parameter estimates are provided in panel $b$. in the first column of Table 3. Both the anticipation effect and the 57.5+ effect get smaller. The anticipation effect is no longer statistically significant, but the $57.5+$ effect remains significant at the 10 percent level. The effect of age at inflow is not statistically different from zero, suggesting that it can be excluded as one of the covariates. A likelihood ratio test $(L R=1.16)$ confirms that the baseline specification is indeed the preferred model.

In panel $c$. of Table 3 we show the relevant parameter estimates if we include age at inflow but not the anticipation effect. Now we find a significant negative effect of age, while the negative effect of the abolishment of the search requirement is still significantly different from zero but substantially smaller than in panel $a$.

In our baseline specifications we postulated that UI recipients start to anticipate the removal of the search requirement 3 months before its actual removal and that the anticipation effect is constant during this period. Table 4 presents the results of several models that make different assumptions regarding the anticipatory behavior of UI recipients. In specification (1), we assume that recipients start to anticipate the change in policy only 1 month before the actual removal. Here, as well as in our baseline specification we find a negative anticipation effect. The anticipation effect is larger than in the baseline specification, but the effect of the removal of the search requirement is the same. In specification (2), we assume that recipients start to anticipate the change in policy in the two months prior to it. Furthermore, we allow the anticipation effect to be different in the first month of anticipation relative to the second month. The estimates of both anticipation effects, however, are very similar, suggesting that the anticipation effect is constant within the two month period. Again, the effect of the removal of the search requirement is the same as in the baseline specification. In specification (3), we assume that recipients start to anticipate the change in policy three months prior to the removal of the search 
requirement. As in specification (2) we allow the anticipation effect to differ across "anticipation months." The results indicate that unemployed workers start to anticipate the removal of the search requirement only in the two months prior to the actual removal.

The results presented so far may be biased when persons are able to choose the age at which they get unemployed. The discussion in section 3 pointed out that, at least before 11 August 2003, there were strong incentives for persons to get unemployed after the age of 57.5, since in that case they can receive unemployment benefits until the mandatory retirement age of 65 . A first indication of this may be provided by the inflow rates by age. These do not show a drop in inflow just before 57.5, but do show a spike just after 57.5. Tuit and Van Ours (2010) conclude, based on the same data as we use, that "workers had some influence on the timing of their unemployment spell and when possible they use this influence to their advantage." So, our results may be biased. Assuming that persons cannot postpone their inflow into unemployment by more than six (three) months, analyzing a sample which consists of person younger than 57 (57 and 3 months) at inflow (and older than 55.5) provides evidence of the sensitivity of our conclusions to the sample. The relevant parameter estimates are presented in Table 5, specifications (1) and (2). In both specifications the 57.5+ effect is statistically significant and the size is the same between the two specifications, but in both cases the effect is larger than in the baseline specification. In specification (1) the anticipation effect is not significant, but in specification (2) it is at the 10 percent level. These results suggest that our conclusions are not sensitive to the "sample selection problem."

So far we have assumed that UI recipients were exempted from the search requirement as of the first day of the month in which they turned 57.5. However, as we do not know when exactly the abolishment was implemented, we estimate two models in which we assume a different moment of abolishment. In specification (3) of Table 5 we assume that the search requirement is removed at the end of the month in which a person turn 57.5, whereas in specification (4) we assume that it is removed at a person's 57.5 "birthday." Across both specifications, the size of the anticipation effect and 57.5+ effect are the same, and in both cases the effects are larger than in the baseline specification. The conclusions based on the results of these last two specifications and are the same as those based on the baseline specification: there is a large negative effect of the removal of the search requirement as well as significant anticipation effects.

As a final sensitivity analysis we estimated our baseline model on inflow data from 2004, to examine whether or findings are indeed due to the removal of the search requirement. The parameter estimates are given in the second column of Table 6. Surprisingly, the results pre- 
sented in panel $a$. indicate that there is still a negative and significant $57.5+$ effect although it is substantially smaller than for the 2001 inflow. However, as shown in panels $b$. and $c$. the $57.5+$ effect disappears once age at inflow is included. Furthermore, once we restrict the sample to UI recipients flowing in after 1 July 2004, we find a 57.5+ effect that does not differ significantly from zero (see panel $d$. of Table 6). These results support the view that the finding of a negative and significant 57.5+ effect when using all inflow from 2004, is due to a delayed implementation of the reform of 1 January 2004. Another explanation may be that HRM departments are not used to receiving job application letters from persons older than 57.5 and therefore put them aside.

\section{Conclusions}

Older workers face a difficult labor market position when they lose their job. Their prospects of finding a new job are not very good. Therefore, unemployment durations among older unemployed workers are relatively long. For a long time the labor market position of older workers in the Netherlands was considered to be so poor, that from age 57.5 onwards, UI recipients were no longer required to actively search for a job although they still had to to accept job offers. In 2004 this rule was abolished and the active search requirement was also imposed upon unemployed workers beyond age 57.5.

In our paper we analyze job finding rates of workers who became unemployed prior to January 2004 over a relatively short age span, from 55.5 to 57.5 years. We are particularly interested in the evolution of the job finding rates as these workers got close to the point were the active search requirement was abolished to find out whether any anticipation effects occurred. Also, we are interested in the magnitude of the effect of the abolishment on the job finding rate. It is not easy to identify an anticipation effect as job finding rates are influenced by duration dependence as well as age dependence. Although we study job finding rates over a relatively small age interval it may still be the case that age at inflow affects the job finding rate. Nevertheless, investigating the job finding rates of these older workers we find that the abolition of the requirement to actively search for a job had a relatively large negative effect. Furthermore, unemployed workers who are getting close to the age of 57.5 reduce their search intensity quite a lot. There is a clear negative anticipation effect.

The fact that unemployed workers anticipate the abolishment of the search requirement by reducing their search effort is not remarkable per se but evidence of rational behavior. If search intensity by unemployed workers would be driven by rational arguments an anticipation effect 
is to be expected. However, there is no rational for the downward shift in search intensity at the moment the search requirement was abolished. It could be that older workers felt obliged to stick to the rules of the game and actually kept on searching until this was no longer formally required. This is all the more remarkable as job search is among the activities which are not very popular among unemployed workers. Knabe, Rätzel, Schöb, and Weimann (2010) for example study life satisfaction measured as a general feeling and momentary satisfaction related to specific activities and find that UI recipients consider being employed as a desirable state but they do not value the activities which would speed up the transition to this state sufficiently. Thus, it makes sense to impose an obligation to unemployed workers to actively search for a job.

Although the absolute increase in the job finding rates among older workers for whom the search requirement is reinstalled is rather small, the fact that there is an increase at all is remarkable given the relatively weak labor market position of older workers. Apparently, even older workers have some influence over their job finding. Extrapolating our findings to younger age categories it is clear that it is important to have well specified search requirement which should be enforced to make sure that UI recipients keep searching for a job irrespective of how long they have been unemployed. Even workers with seemingly poor job prospects seem to benefit from the requirement to actively search for a job.

\section{References}

Abbring, J. H., Van den Berg, G. J., \& Van Ours, J. C. (2005). The effect of unemployment insurance sanctions on the transition rate from unemployment to employment. Economic Journal, 115, 602-630.

Ashenfelter, O., Ashmore, D., \& Deschênes, O. (2005). Do unemployment insurance recipients actively seek work? Evidence from randomized trials in four U.S. States. Journal of Econometrics, 125, 53-75.

Grubb, D. (2001). Eligibility criteria for unemployment benefits. In Labour Market Policies and the Public Employment Service (pp. 187-216). Paris, France: OECD.

Gruber, J., \& Wise, D. (1998). Social security and retirement: an international comparison. American Economic Review, 88, 158-163.

Heyma, A. (2001). Dynamic models of labour force retirement: An empirical analysis of early exit in the Netherlands. Unpublished doctoral dissertation, University of Amsterdam.

Heyma, A., \& Van Ours, J. C. (2006). How eligibility criteria and etitlement characteristics of unemployment benefits affect job finding rates of elderly workers (mimeo). Tilburg University.

Johnson, T., \& Klepinger, D. (1994). Experimental evidence on unemployment insurance work-search policies. Journal of Human Resources, 29, 694-717. 
Katz, L. F., \& Meyer, B. D. (1990). The impact of the potential duration of unemployment benefits on the duration of unemployment. Journal of Public Economics, 41, 45-72.

Klepinger, D., Johnson, T., \& Joesch, J. (2002). Effects of unemployment insurance worksearch requirements: the Maryland experiment. Industrial and Labour Relations Review, $56,3-22$.

Knabe, A., Rätzel, S., Schöb, R., \& Weimann, J. (2010). Dissatisfied with life but having a good day: time-use and well-being of the unemployed. Economic Journal, 120, 867-889.

Lammers, M., Bloemen, H., \& Hochguertel, S. (2013). Job search requirements for older unemployed: Transitions to employment, early retirement and disability benefits. European Economic Review, 58, 31-57.

Lancaster, T. (1990). The econometric analysis of transition data. Cambridge, UK: Cambridge University Press.

McCrary, J. (2007). Manipulation of the running variable in the regression discontinuity design: a density test. Journal of Econometrics, 142, 698-714.

Meyer, B. D. (1990). Unemployment insurance and unemployment spells. Econometrica, 58, 757-782.

Meyer, B. D. (1995). Lessons from U.S. unemployment insurance experiments. Journal of Economic Literature, 83, 91-131.

Mortensen, D. T. (1977). Unemployment insurance and job search decisions. Industrial and Labor Relations Review, 30, 505-517.

OECD. (2006). Live longer, work longer, ageing and employment policies. Paris, France: Author.

Tuit, S., \& Van Ours, J. C. (2010). How changes in unemployment benefit duration affect the inflow into unemployment. Economics Letters, 109, 105-107.

Van den Berg, G. J. (1990). Nonstationarity in job search theory. Review of Economic Studies, $57,255-277$.

Van den Berg, G. J. (2001). Duration models: Specification, identification, and multiple durations. In J. J. Heckman \& E. Leamer (Eds.), Handbook of Econometrics (Vol. V, pp. 3381-3460). Amsterdam, the Netherlands: North-Holland. 
Table 1: Descriptive statistics

\begin{tabular}{lrr}
\hline Variable & 2001 & 2004 \\
\hline Age & 56.4 & 56.4 \\
Sex male (\%) & 84.6 & 82.8 \\
Primary education (\%) & 15.9 & 8.1 \\
Secondary education (\%) & 65.1 & 70.2 \\
Tertiary education (\%) & 19.0 & 21.7 \\
Not alone (\%) & 74.8 & 73.8 \\
Phase 1 (\%) & 85.4 & 82.8 \\
Completed spell (\%) & 40.0 & 31.1 \\
of which: & & \\
$\quad$ Type 1 (\%) & 7.6 & 11.7 \\
$\quad$ Type 2 (\%) & 8.6 & 9.3 \\
$\quad$ Type 3 (\%) & 76.9 & 69.2 \\
Type 4 (\%) & 5.4 & 7.6 \\
$\quad$ Type 5 (\%) & 1.4 & 2.1 \\
\hline Sample size & 1,606 & 2,778 \\
\hline Note that the types of completed spells are ex- \\
plained in the main text.
\end{tabular}


Table 2: Parameter estimates exploratory analysis monthly job finding probabilities

\begin{tabular}{|c|c|c|c|c|c|c|c|c|}
\hline \multirow{2}{*}{2001} & \multicolumn{4}{|c|}{ First 12 months } & \multicolumn{4}{|c|}{ First 6 months } \\
\hline & \multicolumn{2}{|c|}{ (1) } & \multicolumn{2}{|c|}{ (2) } & \multicolumn{2}{|c|}{ (3) } & \multicolumn{2}{|r|}{ (4) } \\
\hline Anticipation effects & -1.59 & $(3.0)^{* *}$ & -1.76 & $(3.4)^{* *}$ & -2.77 & $(3.1)^{* *}$ & -2.72 & $(3.4)^{* *}$ \\
\hline Treatment effect & -0.82 & $(1.5)$ & -1.15 & $(2.7)^{* *}$ & -1.38 & $(1.1)$ & -1.39 & $(1.3)$ \\
\hline \multicolumn{9}{|l|}{2004} \\
\hline Anticipation effect & -0.21 & $(0.4)$ & & & -0.59 & $(0.8)$ & & \\
\hline Treatment effect & 0.59 & (1.6) & & & 0.17 & $(0.2)$ & & \\
\hline Year 2004 & -1.84 & $(8.0)^{* *}$ & -1.80 & $(7.9)^{* *}$ & -2.90 & $(7.8)^{* *}$ & -2.93 & $(7.9)^{* *}$ \\
\hline$N$ & \multicolumn{2}{|c|}{576} & \multicolumn{2}{|c|}{576} & \multicolumn{2}{|c|}{288} & \multicolumn{2}{|r|}{288} \\
\hline
\end{tabular}

Note: All estimates are based on workers entering unemployment before age 57.5. All regressions contain 23 monthly age-at-inflow fixed effects; columns (1) and (2) have 11 monthly duration fixed effects, columns (3) and (4) have 5 duration fixed effects; absolute $t$-statistics based on robust standard errors in parentheses; a ** indicates statistical significance at a $5 \%$ level. 
Table 3: Baseline parameter estimates for 2001

\begin{tabular}{lrl}
\hline a. Baseline specification & & \\
\hline Anticipation $<3$ months & -0.30 & $(2.2)^{* *}$ \\
$57.5+$ effect & -0.65 & $(4.1)^{* *}$ \\
Male & 0.25 & $(1.9)^{*}$ \\
Secondary education & -0.49 & $(4.4)^{* *}$ \\
Tertiary education & -1.05 & $(6.3)^{* *}$ \\
Not alone & -0.08 & $(0.8)$ \\
Phase 1 & 0.99 & $(5.8)^{* *}$ \\
Constant & -6.24 & $(23.9)^{* *}$ \\
Duration dependence & & \\
$\quad$ 3-6 months & -0.30 & $(2.2)^{* *}$ \\
$\quad$ 6-12 months & -1.08 & $(5.2)^{* *}$ \\
$\quad>12$ months & -3.30 & $(10.3)^{* *}$ \\
$v_{2}$ & $-\infty$ & \\
$\eta$ & 1.93 & $(1.3)$ \\
Pr $\left.v=v_{2}\right)$ & 0.13 & \\
-Loglikelihood & $4,727.10$ & \\
\hline b. Including age at inflow & & \\
\hline Anticipation $<3$ months & -0.18 & $(0.9)$ \\
57.5+ effect & -0.49 & $(1.8)$ \\
Age at inflow & -0.15 & $(0.9)$ \\
-Loglikelihood & $4,726.52$ & \\
\hline c. Ignoring anticipation & & \\
\hline 57.5+ effect & -0.39 & $(2.0)^{*}$ \\
Age at inflow & -0.22 & $(2.1)^{* *}$ \\
-Loglikelihood & $4,727.45$ & \\
\hline$N$ & 1,606 & \\
\hline N & & \\
\hline
\end{tabular}

Note that in panel $b$. and $c$. the same specifications as in panel $a$. are used but only the relevant parameters are reported; absolute $t$-statistics in parentheses; a ** indicates statistical significance at a 5\% level. 
Table 4: Specifications with different anticipation intervals; 2001 inflow

\begin{tabular}{|c|c|c|c|c|c|c|}
\hline \multirow[b]{2}{*}{ Anticipation 2-3 months } & \multicolumn{2}{|c|}{ (1) } & \multicolumn{2}{|c|}{ (2) } & \multicolumn{2}{|c|}{ (3) } \\
\hline & & & & & 0.04 & $(0.2)$ \\
\hline Anticipation 1-2 months & & & -0.54 & $(2.2)^{* *}$ & -0.53 & $(2.1)^{* *}$ \\
\hline Anticipation $<1$ months & -0.48 & $(2.0)^{*}$ & -0.51 & $(2.1)^{* *}$ & -0.50 & $(2.1)^{* *}$ \\
\hline $57.5+$ effect & -0.62 & $(4.0)^{* *}$ & -0.65 & $(4.1)^{* *}$ & -0.65 & $(4.1)^{* *}$ \\
\hline -Loglikelihood & $4,727.5$ & & $4,724.7$ & & $4,724.4$ & \\
\hline$N$ & 1606 & & 1606 & & 1606 & \\
\hline
\end{tabular}

Note that the same specifications are used as in Table 3 panel $a$. but only the relevant parameters are reported; absolute $t$-statistics in parentheses; a $* *(*)$ indicates statistical significance at a 5\% $(10 \%)$ level. 
Table 5: Other sensitivity analyses

\begin{tabular}{|c|c|c|c|c|}
\hline & (1) & (2) & (3) & (4) \\
\hline & $\begin{array}{c}\text { Age at inflow } \\
<57\end{array}$ & $\begin{array}{l}\text { Age at inflow } \\
<57+3 \text { months }\end{array}$ & $\begin{array}{l}\text { Removal at } \\
\text { end of the month }\end{array}$ & $\begin{array}{l}\text { Removal at } \\
57.5 \text { birthday }\end{array}$ \\
\hline Anticipation $<3$ months & $-0.09 \quad(0.4)$ & $-0.24 \quad(1.6)$ & $-0.45(3.0)^{* *}$ & $-0.41(2.9)^{* *}$ \\
\hline $57.5+$ effect & $-0.97(3.1)^{* *}$ & $-0.99(4.6)^{* *}$ & $(4.5)^{* *}$ & $(4.9)^{* *}$ \\
\hline -Loglikelihood & $3,938.7$ & $4,438.6$ & $4,722.7$ & $4,721.1$ \\
\hline$N$ & 1274 & 1487 & 1606 & 1606 \\
\hline
\end{tabular}

Note that the same specifications are used as in Table 3 panel $a$. but only the relevant parameters are reported; absolute $t$-statistics in parentheses; a ** indicates statistical significance at a $5 \%$ level. 
Table 6: Parameter estimates of models for 2004

\begin{tabular}{lrl}
\hline a. Baseline specification & & \\
\hline Anticipation $<3$ months & -0.16 & $(1.3)$ \\
57.5+ effect & -0.33 & $(2.3)^{* *}$ \\
Male & 0.68 & $(4.2)^{* *}$ \\
Secondary education & -0.51 & $(2.7)^{* *}$ \\
Tertiary education & -0.87 & $(3.9)^{* *}$ \\
Not alone & 0.07 & $(0.5)$ \\
Phase 1 & 1.42 & $(7.9)^{* *}$ \\
Constant & -6.59 & $(22.6)^{* *}$ \\
Duration dependence & & \\
$\quad$ 3-6 months & 0.35 & $(2.7)^{* *}$ \\
$\quad$ 6-12 months & 0.08 & $(0.4)$ \\
$\quad>12$ months & -0.03 & $(0.1)$ \\
$v_{2}$ & -3.07 & $(11.7)^{* *}$ \\
$\eta$ & -0.94 & $(3.4)^{* *}$ \\
Pr $\left(v=v_{2}\right)$ & 0.72 & \\
-Loglikelihood & $6,790.8$ & \\
\hline b. Including age at inflow & & \\
\hline Anticipation $<3$ months & -0.12 & $(0.9)$ \\
57.5+ effect & -0.28 & $(1.7)$ \\
Age at inflow & -0.08 & $(0.6)$ \\
-Loglikelihood & $6,790.6$ & \\
\hline c. Ignoring anticipation & & \\
\hline 57.5+ effect & -0.21 & $(1.6)$ \\
Age at inflow & -0.10 & $(0.8)$ \\
-Loglikelihood & $6,791.1$ & \\
\hline d. Inflow after 1 July 2004 & & \\
\hline 57.5+ effect & -0.24 & $(1.4)$ \\
-Loglikelihood & $2,810.5$ & \\
\hline & & \\
\hline
\end{tabular}

Note that in panel $b$. and $c$. the same specifications as in panel $a$. are used but only the relevant parameters are reported. The sample size in panels $a ., b$. and $c$. is 2,778, in panel $d$. it is 1262 ; absolute $t$ statistics in parentheses; a ** indicates statistical significance at a $5 \%$ level. 
Figure 1: Inflow into unemployment in 2001

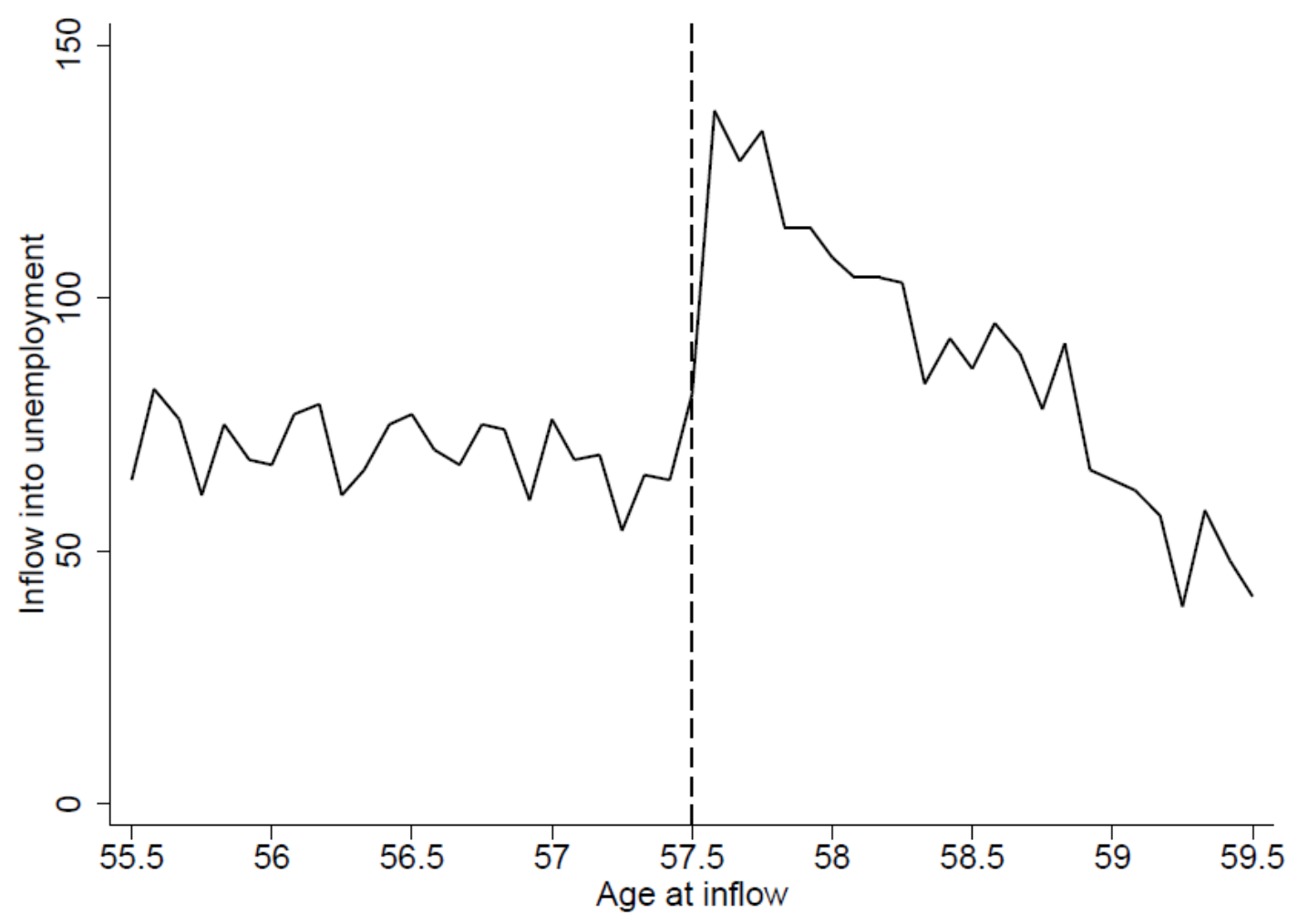


Figure 2: Monthly job finding rates by duration of unemployment

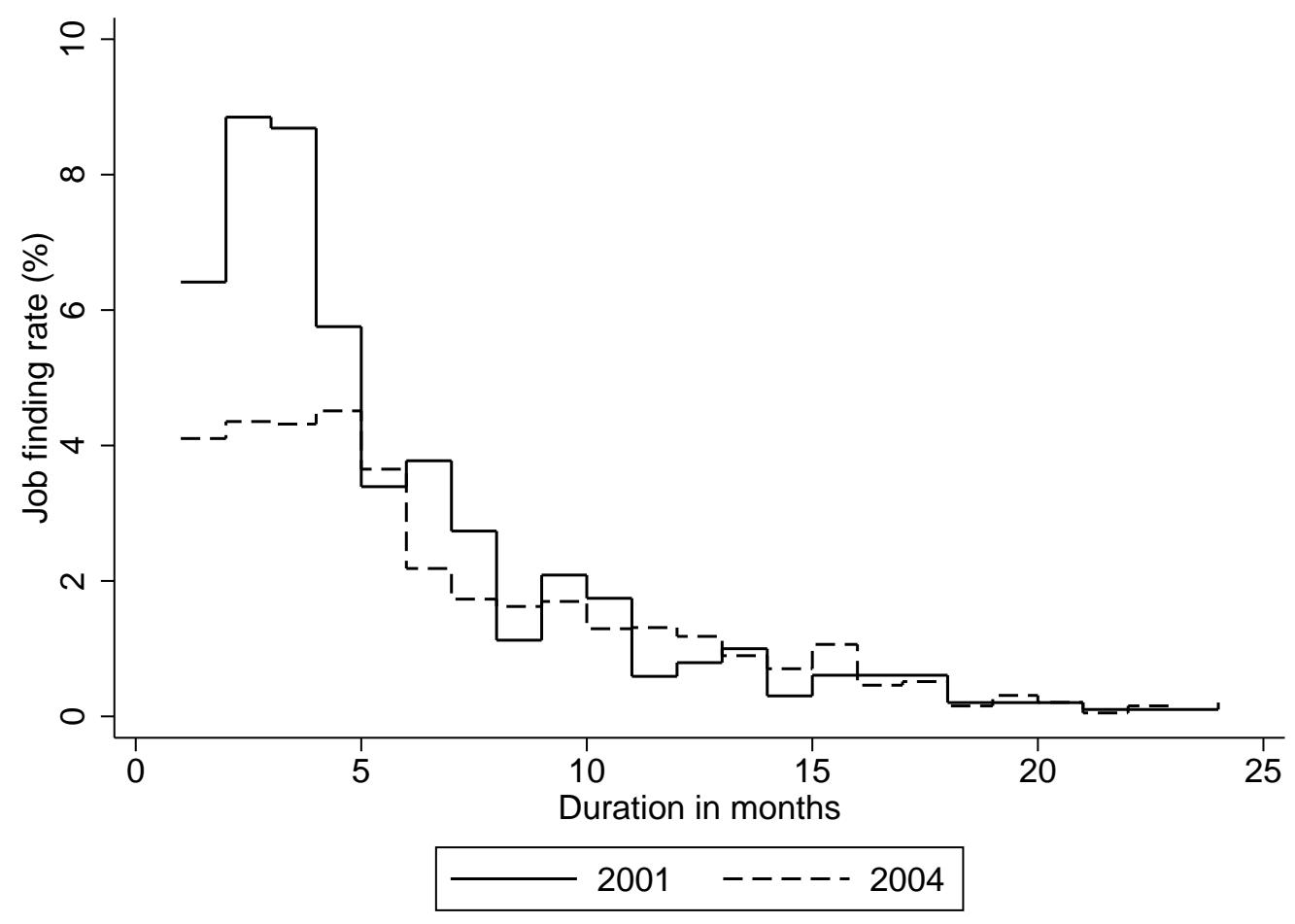


Figure 3: Relative monthly job finding rates in relation to age 57.5

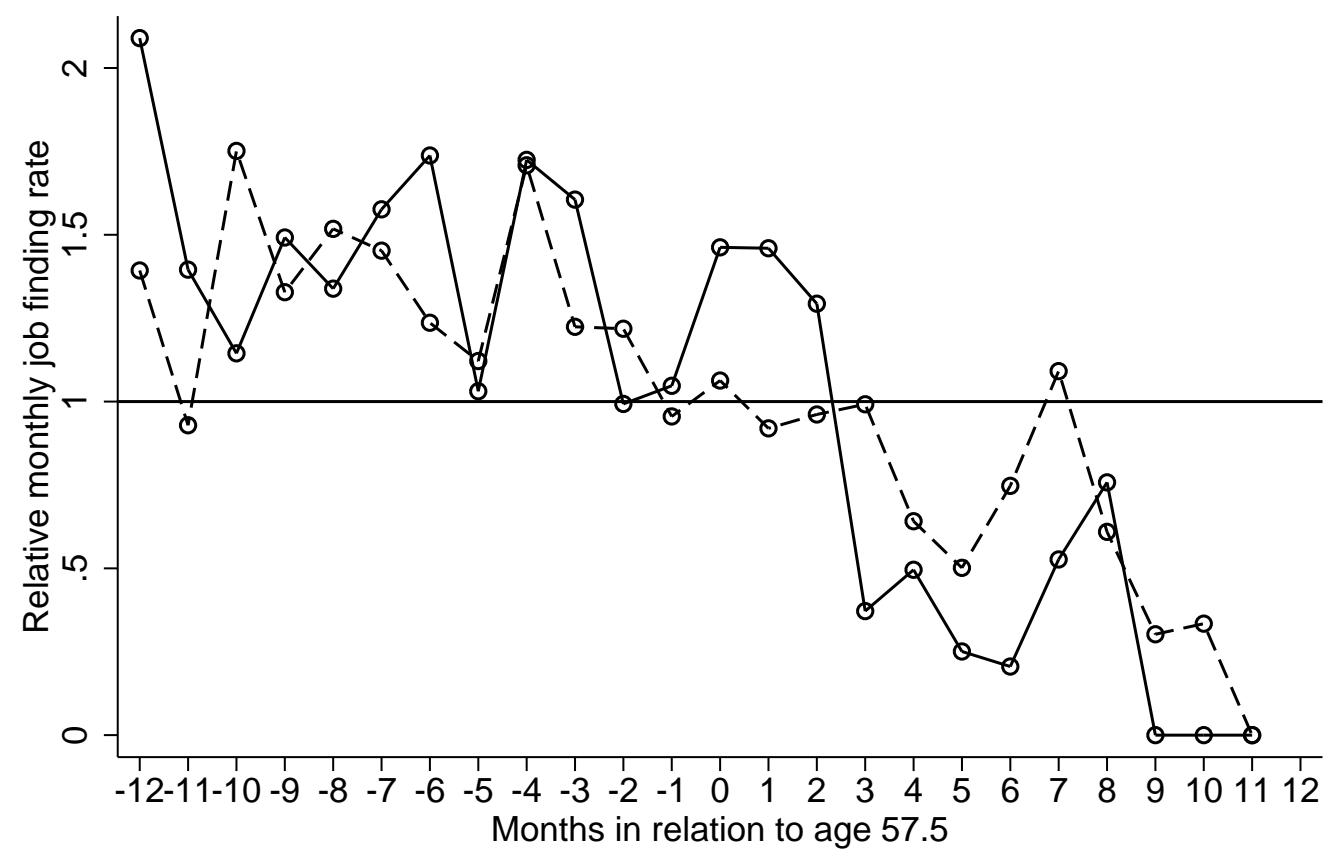

- 2001 - Inflow before $57.5 \quad--\Theta--2004$ - Inflow before 57.5

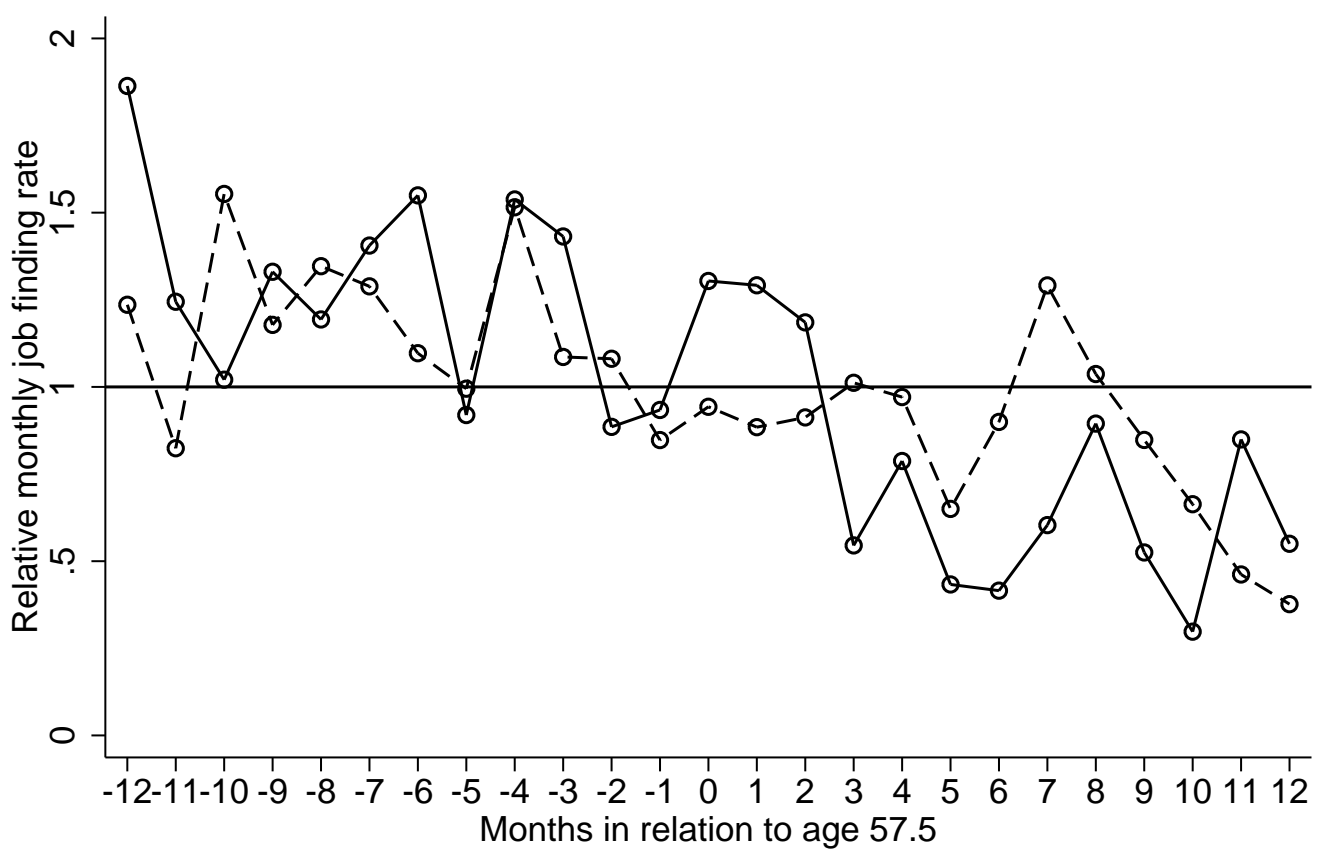

$-0-2001$ (55.5-59.5 at inflow) $\quad--\Theta--2004$ (55.5-59.5 at inflow) 